\title{
Does the Renin-Angiotensin System (RAS) Regulate also Intraocular Pressure (IOP)?
}

\author{
Heikki Vapaatalo*, Anu Vaajanen, Päivi Alajuuma and Olli Oksala
}

Institute of Biomedicine, Pharmacology, University of Helsinki, Finland, Tampere University Hospital, Department of Eye, Ear and Oral Diseases, Tampere, Finland and Santen Oy, Tampere, Finland

\begin{abstract}
The central role of Renin-Angiotensin System (RAS) in the regulation of blood pressure is widely accepted, and drugs which inhibit the formation of the potent vasoconstrictor angiotensin II (AngII) i.e. ACE inhibitors or drugs which block the Ang receptors of type 1 (AT1R) form the cornerstone in the treatment of hypertension. However, from AngI and AngII also vasodilating and blood pressure lowering products, such as Ang(1-7) are formed by another ACE isoenzyme (ACE2). Ang(1-7) acts by stimulating newly described, vasodilatory and antiproliferative Mas-receptors. Furthermore, AngII itself has also vasodilatory and antiproliferative properties via angiotensin type 2 receptors (AT2R). We and others have described different components of RAS in various parts of the eye. It can be suggested that these components play a role in regulation of IOP either by reducing aqueous humour formation or by increasing its outflow or both.
\end{abstract}

Keywords: Renin-angiotensin system (RAS), intraocular pressure (IOP), angiotensin receptors (ATR), Mas-receptor, ACEinhibitor.

\section{INTRODUCTION}

The Finnish physiologists Tigerstedt and Bergman described for the first time a pressor substance from rabbit kidney and named it renin already over hundred years ago. In 1940 's, renin was shown to be an enzyme which breaks down a plasma protein angiotensinogen formed in the liver to a weak vasopressor angiotensin I which is then converted by angiotensin converting enzyme (ACE) to extremely potent vasoconstricting and blood pressure increasing octapeptide angiotensin II (AngII). The same ACE enzyme also metabolizes potent vasodilatory bradykinin to inactive breakdown products. Thus, by acting via these two mechanisms, drugs which inhibit ACE (captopril, enalapril, quinapril, ramipril, etc.) are potent antihypertensive agents widely used in the treatment of moderate or severe hypertension and they have also anti-inflammatory properties.

In addition to the circulating Renin-Angiotensin-System (RAS) (Fig. 1) evidence has accumulated that local RAS regulates long-term changes in a number of organs, e.g. the vasculature (endothelium), adrenal gland, kidney, brain, testis and ovary via the activity of other angiotensins and their receptors. An active intraocular RAS has also been described in the human eye, and drugs inhibiting this system have been shown to lower increased intraocular pressure (IOP) in pilot studies. However, no RAS-agents are in ophthalmological use yet. These issues have recently been dealt by us in the reviews $[1,2]$.

\footnotetext{
*Address correspondence to this author at the Institute of Biomedicine, Pharmacology, University of Helsinki, Finland; Tel: +358 40 5257995; Fax: +358 9 19125048; E-mail: heikki.vapaatalo@helsinki.fi
}

\section{RESULTS}

Using real time PCR we showed for the first time expression of novel Mas-receptors in the eye tissue in addition to the traditional AT1a and AT2 receptors [3]. The mRNA expression of the Mas-receptors was lower than that of AT1a, but markedly higher than that of AT2 receptors in spontaneously hypertensive (SHR) rats, double transgenic hypertensive rats (harboring human renin and angiotensinogen genes) (dTGR) and in normotensive Sprague-Dawley rats, but not in Wistar-Kyoto rats. AT receptor expression was overall more obvious in the retina than in the ciliary body.

Using autoradiography we found that AT1 and AT2 receptors in the retina were more pronounced compared to that in the ciliaris in all the rat groups in keeping with the results of the real time-PCR analysis. The density of the AT1 receptors was higher than that of the AT2 receptors. Longterm treatment of the rats with angiotensin receptor blockers (olmesartan, valsartan) lowered the densities of the receptors in the retina contrary to the inefficacy to change the expression.

Fluorometric assay using porcine eyes revealed markedly higher ACE1 activity in the ciliary body compared to the retina [3]. In the retina the activities of ACE1 and ACE2 were at the same level, whereas the ACE1 activity in the ciliary and vitreous bodies was manifold compared to that of ACE2. It should be stressed that ACE 2 activity was for the first time found in the vitreous and ciliary bodies in addition to its earlier known retinal activity.

The functional role of RAS in regulation of intraocular pressure (IOP) was tested using different compounds acting via RAS and administered intravitreally (Table 1) [2]. The most important and novel finding was IOP lowering effect of 


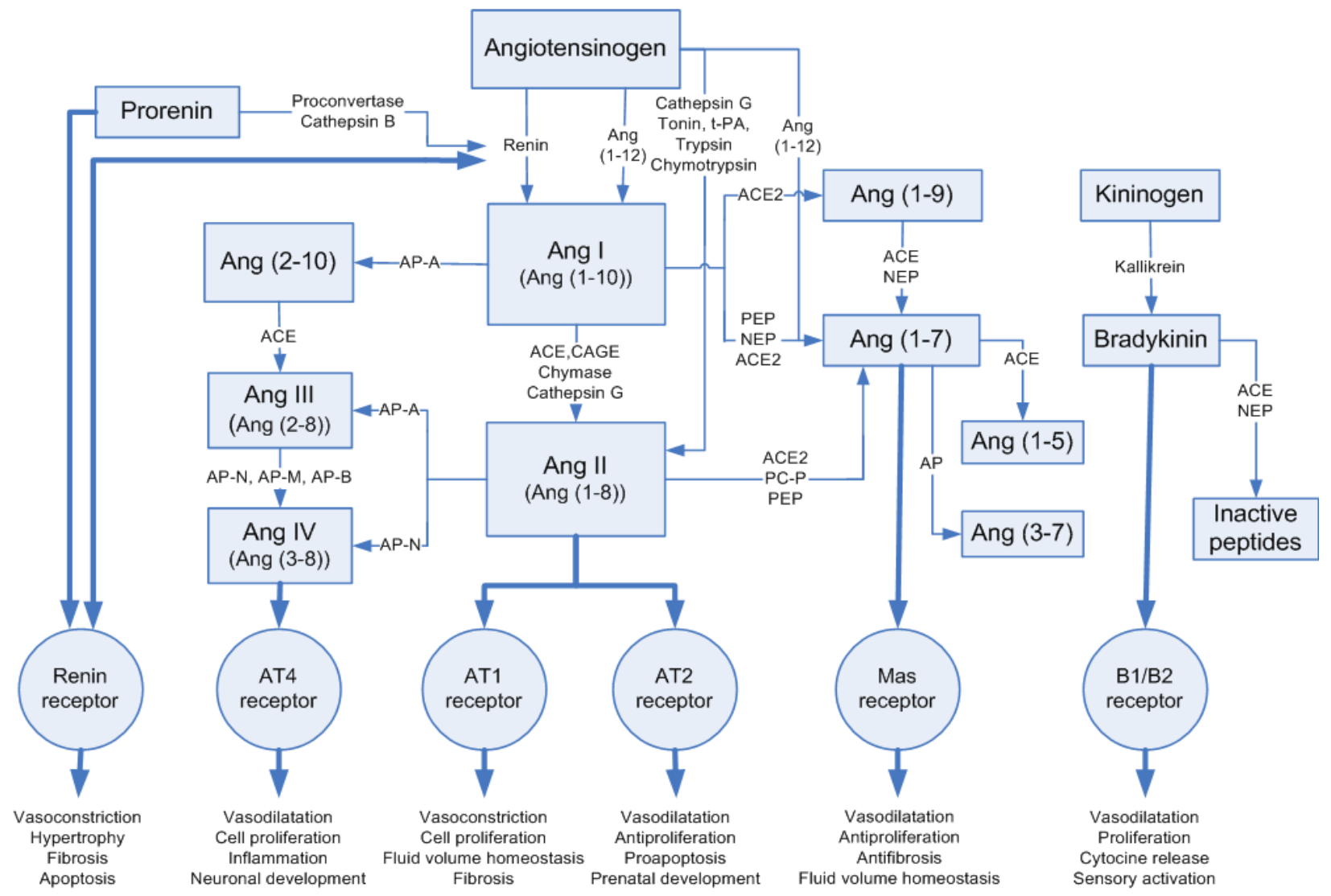

Fig. (1). A Schematic Presentation of the Renin-Angiotensin System. (Vaajanen 2009, modified version) [2].

$\mathrm{ACE}=$ angiotensin-converting enzyme, ACE2 = angiotensin-converting enzyme-related carboxypeptidase, Ang I,II,III,IV = angiotensin I,II,III,IV, Ang (1-10) = angiotensin (1-10), Ang (1-8) = angiotensin (1-8), Ang (2-8) = angiotensin (2-8), Ang (3-8) = angiotensin (3-8), Ang $(1-9)=$ angiotensin (1-9), Ang (1-7) = angiotensin (1-7), Ang (1-5) = angiotensin $(1-5)$, Ang (3-7) = angiotensin (3-7), AT1 = angiotensin II type 1 receptor, AT2 = angiotensin II type 2 receptor, AT4 = angiotensin II type 4 receptor, AP = aminopeptidase $(-\mathrm{A},-\mathrm{N},-\mathrm{M},-\mathrm{B}), \mathrm{B} 1 / \mathrm{B} 2=$ bradykinin receptors, CAGE $=$ chymostatin-sensitive Ang-II generating enzyme, Mas-receptor $=$ Ang $(1-7)$ receptor type, Nep $=$ neprilysin, $\mathrm{PEP}=$ prolyl endopeptidase, $\mathrm{PCP}$-prolylcarboxy-peptidase, $\mathrm{tPA}=$ tissue-type plasminogen activator

Table 1. The Effects of RAS Compounds on IOP in Rabbits After Intravitreal and Topical Administration of Test Agents (Vaajanen 2009, modified version) [2]

\begin{tabular}{|c|c|c|c|}
\hline \multirow[t]{2}{*}{ Compound } & \multirow[t]{2}{*}{ Mechanism of action } & \multicolumn{2}{|l|}{ IOP } \\
\hline & & intravitreal & topical \\
\hline Ang II & AT1 agonist & $\uparrow /-$ & - \\
\hline +olmesartan & AT1 antagonist & $\downarrow^{*}$ & - \\
\hline$+\mathrm{A}-779$ & Mas-receptor antagonist & - & - \\
\hline +olmesartan topically & AT1 antagonist & $\downarrow$ & NA \\
\hline PD123,319 & AT2 antagonist & - & - \\
\hline A-779 & Mas-receptor antagonist & - & - \\
\hline Sar $^{1} \mathrm{Ile}^{8}$ Ang II & Unspecific AT receptor ligand & $\downarrow$ *** & - \\
\hline Olmesartan & AT1 antagonist & $\downarrow$ & - \\
\hline
\end{tabular}

Different concentrations were tested. The main finding was oculohypotensive effect of $1 \mathrm{mM}$ Ang (1-7) when administered intravitreally (50 $\mu$ l). Intravitreally administered Ang II caused dose- dependent rise in IOP $(\uparrow /-) . \uparrow=$ enhance, $\downarrow=$ diminish, $-=$ no effect, NA $=$ not assayed. $* \mathrm{p} \leq 0.05, * * \mathrm{p}<0.005, * * * \mathrm{p}<0.001$. 
Ang(1-7) which was antagonized by a specific Mas-receptor blocker A-779. Also olmesartan, an AT1 receptor antagonist reduced IOP. AngII did not influence IOP. The same was true for CGP42112A, an AT2 receptor agonist.

Neither intracamerally (anterior chamber) administered Ang(1-7) nor an AT2 receptor agonist had any effect on the outflow facility, while AngII reduced it dose - dependently.

\section{CONCLUSIONS}

Glaucoma is worldwide the second leading cause of blindness after cataract. Even though elevated IOP is the major known risk factor for glaucoma and its complications such as optic neuropathy, it is not the only cause. However, the lowering of IOP is still the cornerstone in the treatment of glaucoma and prevention of blindness. Therefore the present findings on the expression of functionally active local RAS in the ocular tissues suggest the potential of agents, which increase ACE 2 activity and thus formation of
Ang(1-7) or activate directly Mas-receptors, as antiglaucomatous drugs in the future.

\section{ACKNOWLEDGEMENTS}

The authors gratefully acknowledge grants from Päivikki and Sakari Sohlberg's Foundation, The Eye Foundation and The Glaucoma Foundation, Finland.

\section{REFERENCES}

[1] Vaajanen, A.; Luhtala, S.; Oksala, O.; Vapaatalo, H. Does reninangiotensin system also regulate intraocular pressure? Ann. Med., 2008, 40, 418-27.

[2] Vaajanen, A. Expression and function of angiotensins in the regulation of intraocular pressure; an experimental study. Thesis, University of Helsinki, Finland 2009.

[3] Vaajanen A.; Lakkisto P.; Virtanen I.; Kankuri E.; Oksala O.; Vapaatalo H.; Tikkanen I. Angiotensin receptors in the eyes of arterial hypertensive rats. Acta Ophthalmol., 2010, 431-8.

(C) Vapaatalo et al.; Licensee Bentham Open.

This is an open access article licensed under the terms of the Creative Commons Attribution Non-Commercial License (http://creativecommons.org/licenses/by-nc/3.0/) which permits unrestricted, non-commercial use, distribution and reproduction in any medium, provided the work is properly cited. 